\title{
THE HISTOCHEMICAL LOCALIZATION OF CYTOCHROME OXIDASE IN THE RETINA AND LATERAL GENICULATE NUCLEUS OF THE FERRET, CAT, AND MONKEY, WITH PARTICULAR REFERENCE TO RETINAL MOSAICS AND ON/OFF-CENTER VISUAL CHANNELS ${ }^{1}$
}

\author{
GLENN H. KAGEYAMA*2 AND MARGARET T. T. WONG-RILEY $\ddagger$ \\ *Department of Anatomy, University of California, San Francisco, California 94143 and $\ddagger$ Department of Anatomy, Medical \\ College of Wisconsin, Milwaukee, Wisconsin 53226
}

Received September 2, 1983; Revised February 3, 1984; Accepted March 21, 1984

\begin{abstract}
The histochemical localization of cytochrome oxidase within the normal retina and lateral geniculate nucleus (LGN) of cats, ferrets, and monkeys revealed that distinct layers, types of cells, and portions of neurons are more intensely stained than others. The dark staining of photoreceptor inner segments and cone pedicles and the light staining of photoreceptor outer segments, somata, and rod spherules demonstrates that different segments of the same cell may have disparate but distinct levels of oxidative enzyme activity. In tangential sections of retina, regular mosaic arrays were evident for each of several darkly reactive retinal components, such as cone inner segments, cone pedicles, and horizontal cells. In the cat and ferret, regular mosaic arrays were also formed by metabolically distinguishable populations of ganglion cells. Ia and IIa ganglion cells (OFF-; Nelson, R., E. V. Famiglietti, Jr., and H. Kolb (1978) J. Neurophysiol. 41: 472-483) were more darkly reactive than the other classes. The darker staining of sublamina a of the inner plexiform layer (OFF-; Famiglietti, E. V., Jr., and H. Kolb (1976) Science 194: 193-195) in the cat and ferret retina, as well as sublamina $\mathrm{A}^{\prime}$ and A1' of the ferret LGN (OFF-; Stryker, M. P., and K. R. Zahs (1983a) J. Neurosci. 3: 19431951) suggest that, under typical rearing conditions, the OFF-channels may be metabolically more active than the ON-channels in these species. In Macaca and Saimiri, darker staining was observed in sublamina b of the inner plexiform layer (ON-; Famiglietti, E. V., Jr., and H. Kolb (1976) Science 194: 193-195) and laminae 1, 2, and 6 of the LGN, implying that, under similar rearing conditions, a different pattern is observed. The dark staining of many large retinal ganglion cells, as well as most of the larger LGN neurons (presumed Y/Y-like), in all species studied is evidence that the $\mathrm{Y} / \mathrm{Y}$-like pathway is also highly active.
\end{abstract}

The histochemical localization of intense cytochrome oxidase (CO; cytochrome $c$ oxidase; ferrocytochrome $c$ : oxygen oxidoreductase EC 1.9.3.1) staining within the highly active primary sensory system and within specific cell types, reported to have high maintained discharge rates, indicates a close relationship between oxidative enzyme staining and regions of elevated physiological activity and oxidative metabolism (Wong-Riley, 1976; Hubel and Livingstone, 1981; Kageyama and Wong-Riley, 1982a). This relationship has also been demonstrated experimentally by noting corresponding changes in $\mathrm{CO}$ staining with changes in neuronal activity induced by deafferentation, sensory deprivation, impulse blockage, or electrical stimulation in both developing and adult animals (Wong-Riley et al., 1978,

${ }^{1}$ This study was supported by National Institutes of Health Research Grant NS 18122. We thank J. Laursen and D. Sullivan for excellent technical assistance and A. Sardinha-Kageyama for assistance in preparing the manuscript.

${ }^{2}$ To whom correspondence should be addressed, at his present address: Department of Developmental and Cell Biology, University of California, Irvine, CA 92717.
1981; Wong-Riley, 1979; Wong-Riley and Welt, 1980; WongRiley and Riley, 1983; Wong-Riley and Carroll, 1984).

In the cat visual system, there are at least three physiologically distinct visual pathways: $\mathrm{X}, \mathrm{Y}$, and $\mathrm{W}$ (Enroth-Cugell and Robson, 1966; Cleland et al., 1971; Stone and Hoffmann, 1972). The cellular components of each pathway have a characteristic distribution within the retina and LGN and are distinguishable on the basis of cell size and dendritic morphology (Guillery, 1966; Boycott and Wässle, 1974; LeVay and Ferster, 1977; Friedlander et al., 1981; Stanford et al., 1981). Y cells, for example, are large compared to the medium-sized $X$ cells and the medium to small $\mathrm{W}$ cells in both the retina and LGN. A similar arrangement has been proposed for the primate visual system (Schiller and Malpeli, 1977; Leventhal et al., 1981; Itoh et al., 1982; Weber et al., 1983).

Earlier, we reported that high levels of oxidative enzyme staining appeared to be restricted mainly to one of the three (X, Y, and W) primary cell types of the cat LGN (Kageyama and Wong-Riley, 1982b). The large (presumed Y) cells were notably more reactive for $\mathrm{CO}$ than the medium (presumed X), while parvocellular lamina $C$ (presumed $W$ ) cells and small (presumed interneurons) cells were the least reactive. However, 
in that study we observed that some of the large cells were only moderately reactive, indicating the possibility of metabolically distinct subclasses of large geniculate neurons. It seemed possible that these two subclasses of geniculate neurons may represent the physiologically characterized $\mathrm{ON}$-center $(\mathrm{ON}-) \mathrm{Y}$ cells and OFF-center (OFF-) Y cells. Since maintained discharge rates have been reported to differ between $\mathrm{ON}$ - and $\mathrm{OFF}$ - subclasses of $\mathrm{X}$ and $\mathrm{Y}$ retinal ganglion cells and geniculate neurons (Stone and Fukuda, 1974; Bullier and Norton, 1979), we hypothesized that cells of $\mathrm{ON}$ - and OFF- visual channels may exhibit different levels of oxidative metabolism.

To test this hypothesis, we examined the retina and LGN of the ferret and rhesus monkey. In the cat retina, there is good evidence that $\mathrm{OFF}$ - and $\mathrm{ON}$ - channels are segregated within distinct sublaminae ( $a$ and $b$, respectively) of the inner plexiform layer (Famiglietti and Kolb, 1976; Nelson et al., 1978; Peichl and Wässle, 1981). In addition, ON- and OFF- sublcasses of $\mathrm{X}$ and $\mathrm{Y}$ cells in the retina form regular and independently arrayed mosaics (Wässle et al., 1981a, b) which can be examined in tangential sections of retina. Thus, we reasoned that physiological differences between distinct types of ganglion cells may result in regularly arrayed mosaics of cells with distinct levels of oxidative enzyme staining. In the LGN of these species, as well as mink and tree shrew, ON- and OFF- channels have also been reported to be segregated into distinct laminae (Schiller and Malpeli, 1978; Conway et al., 1980; LeVay and McConnell, 1982; Stryker and Zahs, 1983a). Thus, the relative levels of CO staining within the $\mathrm{ON}$ - and OFF- laminae in the retina could be compared with the degree of staining within morphologically identifiable ON- and OFF-retinal ganglion cells and with corresponding $O N$ - and OFF-laminae in the LGN of the same animal. Since it was important to know whether closely related animals exhibited similar patterns of metabolic enzyme stain$\therefore$ ng, we also examined the retina and LGN of the cat and scuirrel monkey.

In this study, the normal distribution of $\mathrm{CO}$ within the retina and LGN will also be described, with special emphasis on regularly arrayed mosaics of dark $\mathrm{CO}$-reactive retinal components. A brief report of this material has appeared earlier (Kageyama and Wong-Riley, 1983).

\section{Materials and Methods}

Five pigmented ferrets (Mustela putorius furo), five cats, five rhesus (Macacu mulalla), and five squirrel monkeys (Saimiri sciureus) were used for this study. The ferrets were raised in a shelter with a door that allowed the animals free access to an outside caged area. The cats and monkeys were housed in cages and kept on a regular 12-hr lightdark cycle. All retinae and LGNs were normal and from pigmented adult animals of either sex. After an intraperitoneal injection of sodium pentobarbital (cats and ferrets: $30 \mathrm{mg} / \mathrm{kg}$; primates: $24 \mathrm{mg} / \mathrm{kg}$ of body weight), the anesthetized animals were perfused through the left ventricle with a warm $\left(37^{\circ} \mathrm{C}\right)$ saline flush followed by a cold $\left(4^{\circ} \mathrm{C}\right)$ mixture of $2.5 \%$ paraformaldehyde $/ 1.5 \%$ glutaraldehyde buffered to a $\mathrm{pH}$ of 7.4 with $0.1 \mathrm{M}$ phosphate buffer. The retinae and/or LGNs of the animals were sectioned at 15,30 , and/or $60 \mu \mathrm{m}$ and were histochemically reacted for $\mathrm{CO}$ as described previously (Wong-Riley, 1979). The retinae of each species were sectioned in the tangential and/or transverse planes, while the LGN was sectioned in a plane that optimized the visualization of distinct lamination. Distinct lamination in the ferret LGN was best observed in the parasagittal or horizontal planes (Sanderson, 1974), while the LGN of all other species was cut in the coronal plane.

For controls, sections of retina and LGN were incubated in $\mathrm{CO}$ medium to which 0.01 or $0.001 \mathrm{M} \mathrm{KCN}$ was added.

Cellular analysis. Darkly reactive and moderate to lightly reactive cells were traced at $\times 265$ or $\times 425$ with a drawing tube and were represented as solid and open circles, respectively (see Fig. 3B). LGN neurons were measured from sections that were lightly counterstained with Nissl stain. Dark and moderately reactive cells were traced and numbered separately, and the cross-sectional areas were digitalized via Bioquant Hipad fed into an Apple IIe computer. The degree of regular- ity of the CO-reactive retinal mosaics was determined by using the nearest neighbor analysis (Wässle and Riemann, 1978). The ratio between mean nearest neighbor distance and standard deviation $(\overline{\mathrm{X}}$ $\mathrm{SD}$ ) was used as a measure of the degree of regularity. Higher values of this ratio represent greater regularity.

\section{Results}

\section{CO histochemistry of the retina}

Cross-sections of $\mathrm{CO}$-reacted retinae from ferret, cat, and monkeys are shown in Figure 1. The laminar pattern of oxidative enzyme staining was quite similar in both carnivores and primates (see also Wong-Riley and Carroll, 1984) with the exception of the inner plexiform layer (IPL) and retinal gan. glion cells (RGCs). This pattern of staining was completely inhibited by $0.001 \mathrm{M} \mathrm{KCN}$.

In all species examined, the most intense oxidative enzyme staining was observed within the inner segments of rods and cones. In this layer, cones were more reactive than rods. This was clearly observed in tangential sections where the darkly reactive cone inner segments formed a regularly arrayed mosaic $(\overline{\mathrm{X}} / \mathrm{SD}=10.08,9.75,5.12$, and 5.72 for rhesus monkey, squirre monkey, ferret, and cat, respectively) (see Fig. $2 A$ and Table I). At the FM level, both rod and cone inner segments were reactive, but the cones contained darkly reactive mitochondria that were larger and more densely packed than those in rods (Fig. 2E). The contrast in reactivity between cones and rods was notably greater for the primates than carnivores. The photoreceptor outer segment layer and outer nuclear layer were only lightly reactive.

In the outer portion of the outer plexiform layer (OPL), darkly reactive punctate structures were observed at regular intervals (small arrows, Fig. 1). These puncta were smaller and distributed at shorter intervals centrally, and they were larger and distributed at greater intervals peripherally (compare Fig. $1, D$ and $E$ ). In tangential sections of the OPL, these punctate structures had a regularly arrayed spatial distribution $(\overline{\mathrm{X}} / \mathrm{SD}=7.37,6.60,5.33$, and 5.05 for rhesus monkey, squirrel monkey, ferret, and cat, respectively) comparable to the cone inner segments and were, therefore, identified as cone pedicles (Fig. 2B). This identification was confirmed at the EM level (Fig. $2 F$ ). In the species examined, several large, darkly reactive mitochondria were commonly observed within cone pedicles. In the cat, these mitochondria were often directly apposed to one another and formed a large mitochondrial complex. The less frequently observed mitochondria within rod spherules were usually small and only lightly reactive.

Aside from the cone pedicles, the outer two-thirds of the OPL appeared quite unreactive. Within the inner third of the OPL and the outer half of the inner nuclear layer (INL), however, darkly reactive cells and processes were observed. Based on their location, these cells were identified as horizontal and bipolar cells. In cross-sections of primate peripheral retina, many of these cells were horizontally oriented and fusiform in shape. They were smaller, rounded, and more densely packed closer to area centralis (or parafoveal region). Darkly reactive horizontal cells were also identified in tangential sections of the outer INL of rhesus monkey peripheral retina (Fig. $2 C$ ). They were of uniform size and formed a regular mosaic array $(\overline{\mathrm{X}} / \mathrm{SD}=6.52)$. The layer of horizontal cells was also identified by a very rich vermicular network of evenly spaced blood vessels. Figure $1, B$ and $D$ (large arrowheads), shows that the presence of these blood vessels is prominent mainly within the outer INL or dark reactive horizontal cell layer. Smaller (6 to $7 \mu \mathrm{m}$ ) moderate to darkly reactive cells were also present within the horizontal cell layer (arrows, Fig. 2C). Based on their size, vertical orientation, and concentration within the middle and outer INL, they were identified as bipolar cells. In transverse 


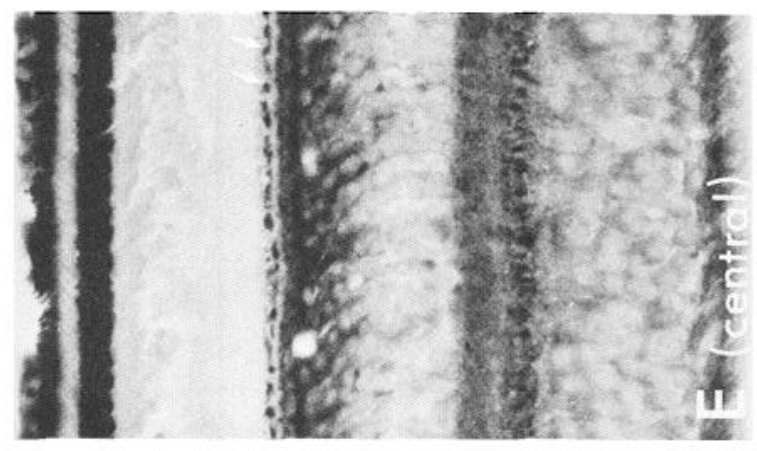

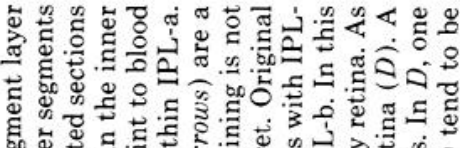

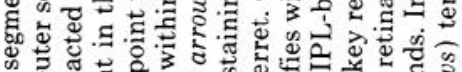

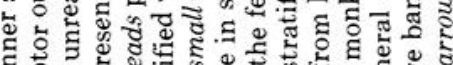

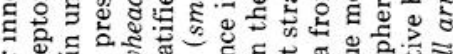

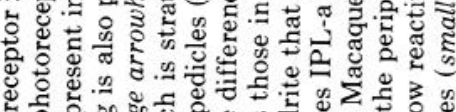

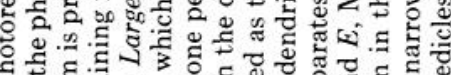

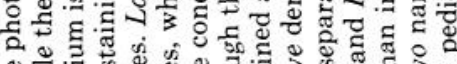

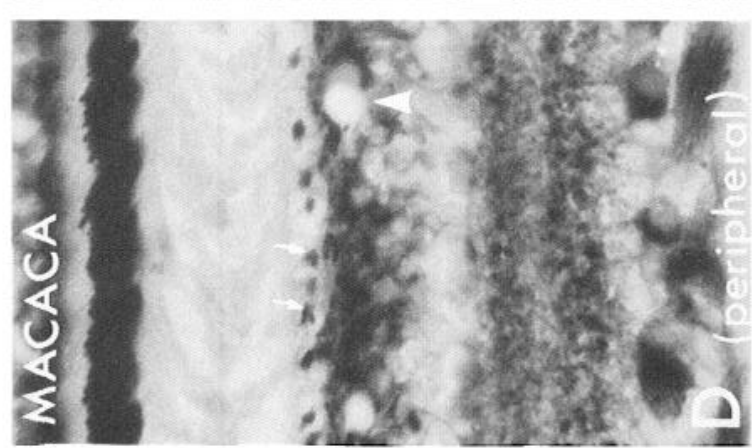

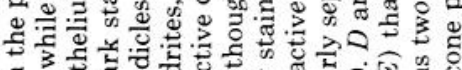

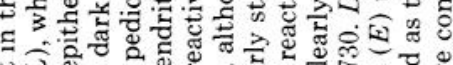

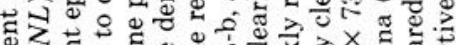

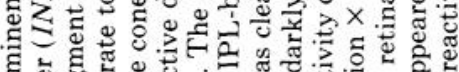
हैं

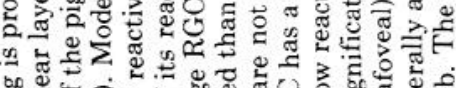

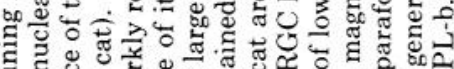

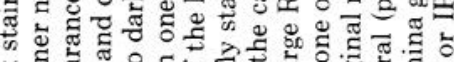

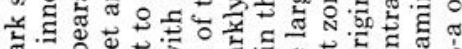

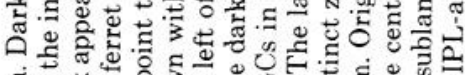

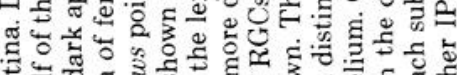
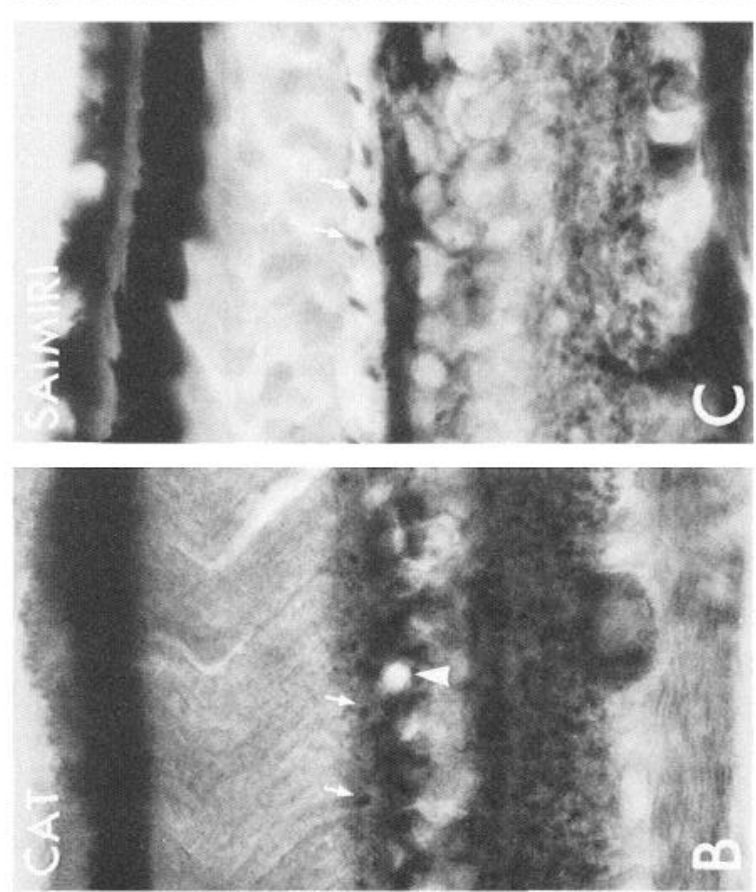

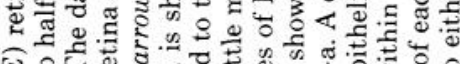

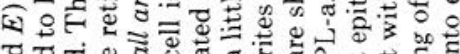

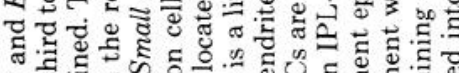
Q

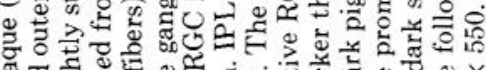
ซำ

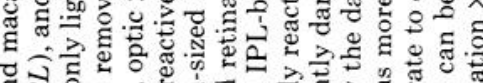
马녕

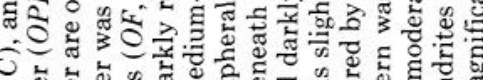

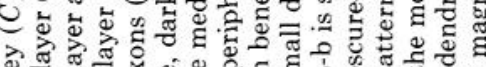

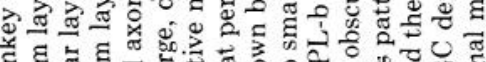

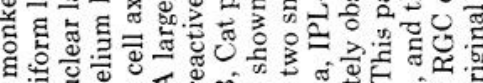

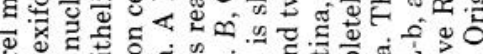

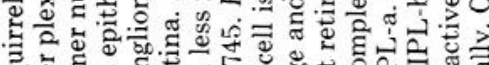

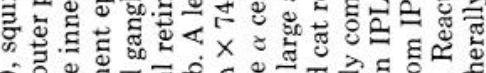

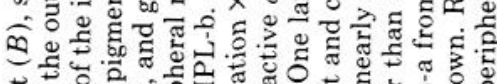

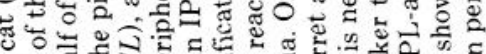

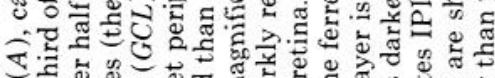

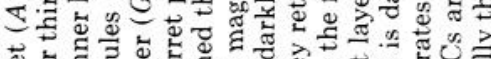

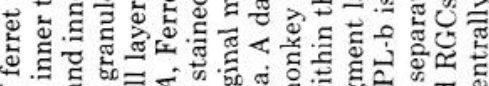
. . 纯

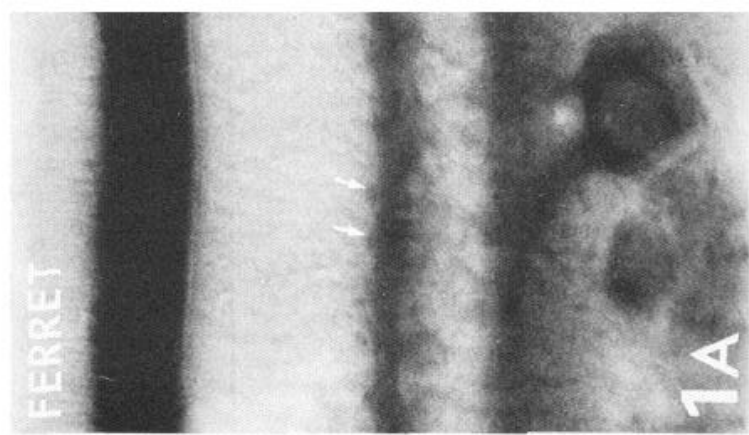

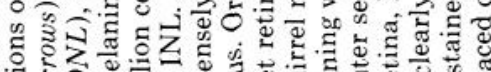

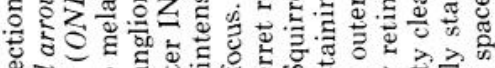
क्ष \% o

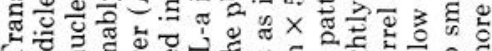

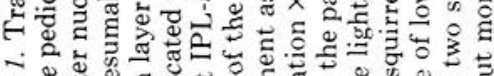
亏ั0 s.

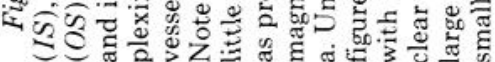



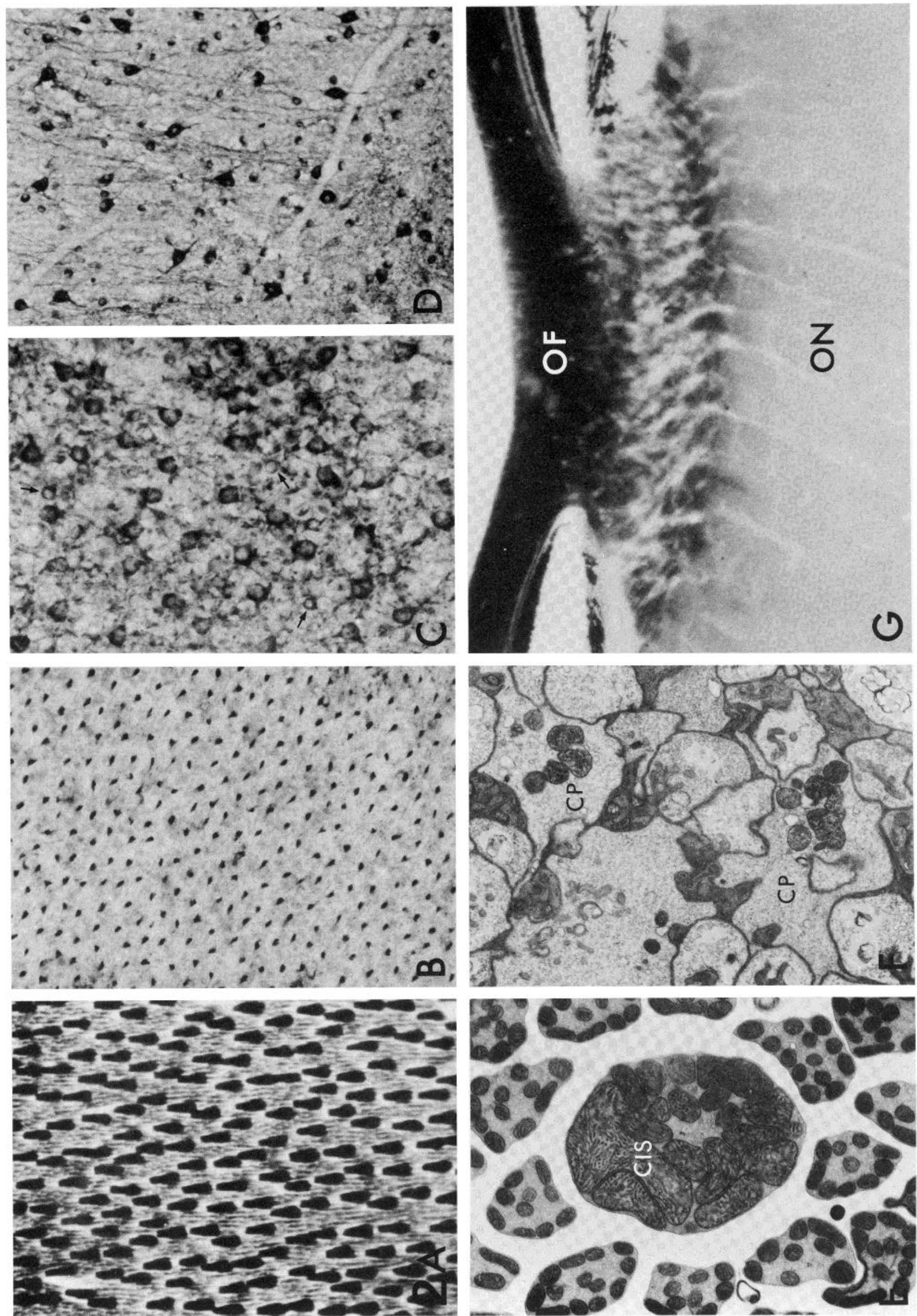
TABLE I

Regularity $(\bar{X} / S D)$ in the mosaic distribution of various $C O$-reactive structures in the retina of the ferret, cat, and monkey

The degree of regularity ( $\overline{\mathrm{X}} / \mathrm{SD})$ for various retinal mosaics was determined from areas of tangential sections that exhibited uniform staining of large numbers of mosaic units. The mean nearest neighbor distance $(\overline{\mathrm{X}})$ was determined and divided by the standard deviation (SD) as described by Wässle and Riemann (1978). For several of the retinal mosaics, the exact eccentricity was not known because the sections were cut from pieces of retina separated from recognizable landmarks, such as the optic disk, area centralis, or fovea. For such mosaics, the eccentricity is simply indicated by a $\mathrm{P}$ (peripheral retina). The number of nearest neighbor units measured $(N)$ and the density of the units are also listed in the table. $\overline{\mathrm{X}} / \mathrm{SD}$ represents an index of regularity, with higher values signifying greater precision. RGCs were distinguished by size, relative degree of enzyme staining, and presence or absence of a darkly stained apical dendrite.

\begin{tabular}{|c|c|c|c|c|c|c|}
\hline Structure & Eccentricity & $N$ & $\bar{X}$ & SD & $\overline{\mathrm{X}} / \mathrm{SD}$ & Density \\
\hline & $m m$ & & $\mu m$ & & & $n o . / m m^{2}$ \\
\hline \multicolumn{7}{|l|}{ Cone inner segment } \\
\hline Macaca & (P) & 100 & 8.96 & 0.89 & 10.08 & 11,000 \\
\hline Cat & (P) & 100 & $7: 25$ & 1.27 & 5.72 & 10,800 \\
\hline Ferret & (P) & 100 & 5.43 & 1.06 & 5.12 & 19,600 \\
\hline \multicolumn{7}{|l|}{ Cone pedicles } \\
\hline Cat & (P) & 326 & 6.58 & 1.30 & 5.05 & 12,700 \\
\hline Ferret & (P) & 100 & 5.70 & 1.07 & 5.33 & 16,500 \\
\hline \multicolumn{7}{|l|}{ Horizontal cells } \\
\hline Macaca & (P) & 177 & 23.73 & 3.64 & 6.52 & 1,200 \\
\hline \multicolumn{7}{|l|}{ Large $(\alpha)$ cells } \\
\hline Dark & 5 & 40 & 255.00 & 67.40 & 3.78 & 8 \\
\hline Moderate & 5 & 36 & 258.90 & 72.70 & 3.56 & 7 \\
\hline \multicolumn{7}{|l|}{ Ferret } \\
\hline Dark + moderate & 3 & 25 & 138.70 & 47.60 & 2.91 & 33 \\
\hline Dark + moderate & 1 & 142 & 102.00 & 41.80 & 2.44 & 48 \\
\hline Dark & 1 & 71 & 162.30 & 40.80 & 3.98 & 25 \\
\hline Moderate & 1 & 66 & 150.60 & 41.50 & 3.63 & 23 \\
\hline \multicolumn{7}{|l|}{ Saimiri } \\
\hline Dark & 4 & 60 & 132.30 & 11.79 & 2.74 & 250 \\
\hline \multicolumn{7}{|l|}{ Macaca } \\
\hline Dark & (P) & 39 & 120.60 & 41.30 & 2.92 & 94 \\
\hline \multicolumn{7}{|l|}{ Medium-sized $(\beta)$ cells } \\
\hline
\end{tabular}

sections, the vertically oriented dendrites and axons of these cells also exhibited moderate to dark staining. The bipolar cells located in the outer INL tended to be more intensely stained than those in the middle INL.
In the lower half of the INL, the cells exhibited relatively low oxidative enzyme activity. While it is possible that some of these lightly stained cells could have been bipolar cells, we presume that most of them were amacrine cells, based simply

Figure 2. Differential staining of retinal components. $A$ to $D, \mathrm{CO}$-reactive retinal mosaics in tangential sections of peripheral retina in $M a c a c a$. $A$, Darkly reactive cone inner segments are regularly arrayed and notably more intensely stained than rod inner segments. Magnification $\times 250$ $B$, Darkly reactive cone pedicles exhibit the same degree of regularity of spacing as cone inner segments $(A)$ and are much more intensely stained than rod spherules. Magnification $\times 250$. C, Darkly reactive horizontal cells located in the outer INL exhibit uniformity with respect to their staining intensity and regular spacing. A few smaller moderately to darkly stained presumed bipolar cells are indicated by small arrows. Magnification $\times 250 . D$, Darkly reactive large RGCs are shown to be regularly arrayed. Numerous moderately to darkly stained medium and small RGCs are also distributed throughout the field. A few darkly stained RGC axons can be seen crossing vertically across the field. Magnification $\times 138$. $E$ and $F$, Electron micrographs of ferret retina. $E$, Electron micrograph of photoreceptor outer segments. Although the mitochondria within both rod and cone outer segments exhibit reactive cristae, cone inner segments (CIS) contain larger and more closely packed mitochondria than do rods. Magnification $\times 14,000$. F, Electron micrograph of photoreceptor terminals. Three cone pedicles are shown among smaller rod spherules. Two of the cone pedicles $(C P)$ contain an aggregate of darkly reactive mitochondria. The other cone pedicle (unlabeled) contains two small darkly reactive mitochondria. Other mitochondria may have been present but are not seen in this section. Rod spherules were seldom seen with reactive mitochondria. Magnification $\times 7,000$. $G$, Transverse section of squirrel monkey optic disk. The darkly reactive unmyelinated segments of $\mathrm{RGC}$ axons (OF, optic fibers) appear to become lightly reactive at the site of myelination, where the optic nerve $(O N)$ begins. The transition from dark to light staining occurs within lamina cribosa (not labeled). Magnification $\times 100$. 
on their location. Moderately reactive amacrine cells were quite rare. The only darkly reactive cells observed within the inner INL were a few large (presumed) displaced ganglion cells.

In the IPL, differences in staining intensity between sublamina a (IPL-a) and sublamina b (IPL-b) were observed in both carnivores and primates. Although both sublaminac exhibited moderate to dark reactivity, IPL-a (OFF-) in the ferret and cat was more intensely stained than IPL-b $(\mathrm{ON}-)$, while in the rhesus and squirrel monkeys IPL-b was usually more reactive than IPL-a (Fig. 1). In the retina of the rhesus monkey this pattern was more pronounced centrally in the parafoveal region (Fig. $1 E$ ) than peripherally (Fig. $1 D$ ). In the primate retina, a narrow zone of low reactivity clearly separated IPL-a from IPL-b, and in some sections IPL-a and IPL-b were each further subdivided into two thin reactive bands, having the appearance of two parallel sets of railroad tracks (Fig. 1D). At the EM level, moderately to darkly reactive mitochondria were observed within ganglion cell dendrites and vesicle-containing profiles of bipolar and amacrine cell processes.

In each species, retinal ganglion cells were usually moderately to darkly reactive for $\mathrm{CO}$. In the cat and ferret, distinct classes were discerned according to their size and degree of reactivity. Such distinctions were not as clear in the primates. Each animal exhibited slightly different patterns of RGC staining. Therefore, they will be discussed below by species.

One final pattern of oxidative enzyme staining shared by all species was the moderate to dark staining of the unmyelinated optic fibers (OFs) subjacent to the RGC layer. Reactive axons were observed in both transverse (Fig. $1, B$ to $E$ )) and tangential sections (Figs. $2 D$ and $3 C$ ), and the presence of darkly reactive mitochondria was confirmed at the EM level. However, the intensity of staining within these axons decreased dramatically at the site (lamina cribosa) where OFs become myelinated (Fig. $2 G$; compare optic fiber $(O F)$ with optic nerve $(O N)$ ). Crosssections of both optic nerve and optic tract consistently exhibited very low levels of $\mathrm{CO}$ staining.

\section{$R G C s$}

In the ganglion cell layer, individual RGCs were clearly distinguished with respect to size and staining in both tangential and transverse sections (Figs. $1, A$ to $D, 2 D$, and $3, A, C$ to $E)$. A class of large ganglion cells was distinguished from medium to small RGCs. However, the absolute size of these classes of RGCs varied by species and with respect to retinal eccentricity. RGCs were smaller and more densely distributed centrally (except for the fovea where they were absent) and larger but less densely distributed peripherally. Distinct patterns of histochemical staining were observed in RGCs for each species.

Cat RGCs. In the cat, RGCs have been distinguished on the basis of their relative size and distribution and correlated with distinct physiological classes (Boycott and Wässle, 1974). A close correspondence has been shown between large $(\alpha)$, medium-sized $(\beta)$, and medium to small $(\gamma)$ cells and physiologi- cally characterized brisk-transient (Y), brisk-sustained (X), and sluggish (W) cells (Enroth-Cugell and Robson, 1966; Cleland et al., 1971; Stone and Hoffman, 1972), respectively.

In tangential sections of area centralis in the cat retina, two populations of large (20 to $25 \mu \mathrm{m}$ diameter) RGCs $(\alpha)$ were distinguished from the more numerous, denscly packed, small $(8 \mu \mathrm{m})$, moderately to lightly reactive RGCs (presumed mostly $\beta$ ) (Fig. 3A). One population of $\alpha$ cells was darkly reactive, while the other was lightly to moderately reactive. The distribution of darkly and moderately to lightly reactive $\alpha$ cells is diagrammed as solid and open circles in Figure $3 B$. A nearest neighbor analysis of $140 \alpha$ cells in the central retina (which included the field shown in Fig. $3 A$ ) revealed that, while $\alpha$ cells as a whole were arrayed with some degree of regularity $(\overline{\mathrm{X}} / \mathrm{SD}$ $=2.86$ ), a greater degree of regularity was observed for the darkly reactive $(\overline{\mathrm{X}} / \mathrm{SD}=4.94)$ or the moderately to lightly reactive $(\overline{\mathrm{X}} / \mathrm{SD}=4.31) \alpha$ cells when they were analyzed as independently arrayed populations. Together, darkly and moderately to lightly reactive $\alpha$ cells were more densely distributed within the central retina and rapidly decreased in density peripherally. The $\alpha$ cell densities at eccentricities $0.25,0.50$, $0.75,1.00$, and $6.00 \mathrm{~mm}$ were, respectively, $143,129,95,81$, and 15 cells $/ \mathrm{mm}^{2}$.

In the peripheral retina (eccentricity $=6$ to $7 \mathrm{~mm}$ ) $\alpha$ cells were larger (30 to $40 \mu \mathrm{m}$ ) but less densely distributed $\left(15 / \mathrm{mm}^{2}\right)$ than those within the central retina. Distinct darkly and moderately to lightly reactive populations were observed. A nearest neighbor analysis of $76 \alpha$ cells from superimposed drawings of adjacent peripheral sections demonstrated that darkly and moderately to lightly reactive $\alpha$ cells were arrayed $(\overline{\mathrm{X}} / \mathrm{SD}=$ 3.78 and 3.56 , respectively) less precisely than observed centrally. Darkly reactive medium-sized (14 to $18 \mu \mathrm{m}$ ) RGCs (presumed $\beta$ cells) were also present in the peripheral retina. They were distributed among moderately to lightly reactive medium (14 to $18 \mu \mathrm{m})$ and lightly reactive small (10 to $12 \mu \mathrm{m})$ RGCs. Thus, while only one population of large $(\alpha)$ RGCs was darkly reactive centrally, in the peripheral retina darkly reactive RGCs could be either large $(\alpha)$ or medium $(\beta)$ in size.

In transverse sections of peripheral retina, moderately reactive RGC dendrites were occasionally observed in continuity with their somata. Thirty-four moderately to darkly reactive $\alpha$ and 103 presumed $\beta$ cells were observed with dendrites that could be traced to the IPL. Of these, $30(88 \%) \alpha$ and $88(85 \%)$ $\beta$ cells had dendrites that traversed IPL-b to stratify within IPL-a. The reactive dendrites of $\alpha$ cells were usually obliquely oriented and curved with a slight arch into IPL-a. The reactive dendrite(s) of $\beta$ cells, in contrast, usually consisted of a single vertically oriented apical dendritic trunk that did not branch until it reached IPL-a. Although reactive dendrites of both $\alpha$ and $\beta$ cells were also observed to terminate within IPL-b, they were never traced at any length within this layer. It is possible that some of these dendrites were destined for IPL-a but were cut in the process of sectioning.

Ferret $R G C s$. In the ferret retina, large RGCs $(20$ to $26 \mu \mathrm{m})$

Figure 3. RGC mosaics. $A$ to $C$, Tangential sections of the ganglion cell layer of cat retina. $A$, Area centralis of cat retina. Two populations of large $\alpha$ cells can be distinguished. One population is darkly reactive, while the other is moderately to lightly reactive. Three moderately to lightly reactive $\alpha$ cells are indicated by arrows. The smaller, presumed $\beta$ cells are also moderately to lightly reactive. Magnification $\times 120$. $B$, The regularly arrayed distribution of the darkly versus moderately to lightly reactive $\alpha$ cells is more clearly seen diagrammatically. Solid circles represent the darkly reactive $\alpha$ cells, and the open circles represent the moderately to lightly reactive $\alpha$ cells of $A$. $C$, Peripheral tangential section of cat retina (eccentricity $=6 \mathrm{~mm}$ ). Darkly and moderately to lightly reactive large RCGs can also be distinguished in the peripheral retina. Two moderately reactive $\alpha$ cells are indicated by arrows. Darkly and moderately to lightly reactive medium-sized RGCs can also be distinguished, as well as a few lightly reactive small RGCs. Magnification $\times 120 . D$ and $E$, Transverse and tangential sections of the ferret retina. $D$, Transverse section of perpheral retina. Darkly reactive medium-sized $\mathrm{KGCs}$ are indicated by small arrows. Each of these RGCs has a single reactive apical dendrite that stratifies within IPL-a. The other medium and small RGCs tend to be less reactive. The large arrow points to a dark reactive large RGC. Magnification $\times 230$. E , Tangential section of the IPL of the central retina of ferret. Dark reactive dendrites of medium-sized RGCs ( small arrows) and of large RGCs (large arrows) are shown traversing IPL-b to stratify within IPL-a. They form a highly ordered retinal mosaic. Magnification $\times 225$. 

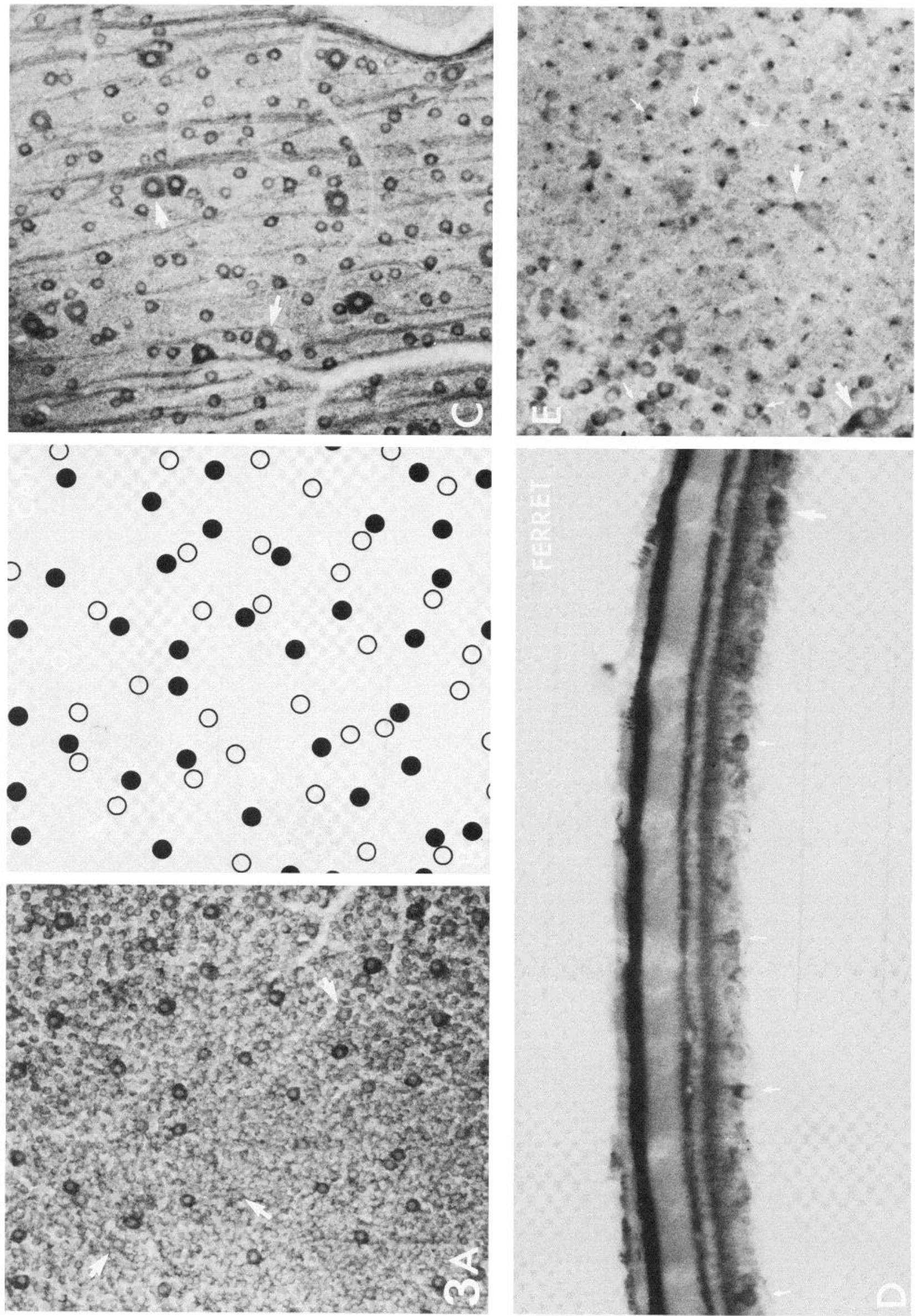

కั้ 
were clearly distinguishable from those that were medium to small (12 to $16 \mu \mathrm{m})$ (Fig. $5 A$ ). In tangential sections, the large RGCs appeared to form two regularly arrayed mosaics, one with darkly reactive dendrites and the other with lightly to moderately stained dendrites. Those large RGCs with the darkly reactive dendrites also tended to have slightly darker stained somata. As a whole, large RGCs were more densely distributed centrally than peripherally and exhibited a degree of regularity $(\overline{\mathrm{X}} / \mathrm{SD}=2.91)$ similar to that of the $\alpha$ cells in the cat.

Although large cells were prominently stained in tangential sections, they represented only a small proportion ( $3 \%$ at eccentricity $=1 \mathrm{~mm}$ ) of the total RGCs. Most of the RGCs in the ferret were medium in size. Of these, nearly half were darkly reactive and regularly arrayed $(\overline{\mathrm{X}} / \mathrm{SD}=3.38)$. It was not unusual to find two darkly reactive medium-sized cells in close proximity to each other. When such pairings occurred, one member of the pair was usually associated with a single small ( 2 to $3 \mu \mathrm{m}$ diameter) round area of intensified reactivity, displaced to one side of the cell. These intensely reactive spots were identified as reactive apical dendrites, and they were present in most $(80 \%)$ of the darkly reactive medium-sized neurons. A nearest neighbor analysis of the darkly reactive dendrites revealed that they were even more precisely arrayed $(\overline{\mathrm{X}} / \mathrm{SD}=6.05)$ than the darkly reactive medium $\mathrm{RGC}$ somata (Fig. $3 E$ ). Each reactive dendrite was either traced serially to a darkly reactive $\mathrm{RGC}$ or could be traced to a reactive cell in the same section. The darkly stained dendrites and somata of these cells were also clearly observed in transverse retinal sections. Darkly reactive medium-sized cells, each with a single reactive apical dendrite, were distributed at regular intervals (Fig. $3 D$ ). The localization of the intensely reactive spots to dendrites was also confirmed at the EM level. These reactive dendrites were 2 to $3 \mu \mathrm{m}$ in diameter and were characterized by their electrondense cytoplasm which contained numerous darkly stained mitochondria. Their appearance was similar to that described for $\beta$ ganglion cell dendrites in the cat retina (Stevens et al., 1980 ). No attempt was made to determine the regularity in the distribution of moderately to lightly reactive medium and/or lightly reactive small $\mathrm{RGCs}$, since they appeared to represent mixed populations of cell types and were not easily distinguishable.

In transverse sections, darkly reactive dendrites were observed in continuity with their somata in 74 large and 148 medium-sized RGCs (see Table II). Of these, the reactive dendrites of $62(84 \%)$ large and $145(98 \%)$ medium-sized RGCs were stratified within IPL-a. Reactive dendrites seldom appeared to stratify within IPL-b, and they were not observed at all in continuity with small RGCs.

Monkey $R G C s$. In the central (parafoveal) region of the primate retina, RGCs tended to be small, densely packed, and only moderately stained (Fig. $1 E$ ). In contrast, peripheral RGCs were predominantly darkly to moderately reactive. The absolute range of RGC cell size differed greatly between Saimiri and Macaca. Moreover, cell size classes were not as distinct in the primate retina as they were in the carnivores. In Saimiri, the large (12 to $15 \mu \mathrm{m}$ ), medium (10 to $12 \mu \mathrm{m}$ ), and small ( 6 to $10 \mu \mathrm{m}$ ) classes of RGCs were notably smaller than the corresponding large (19 to $25 \mu \mathrm{m})$, medium (14 to $19 \mu \mathrm{m}$ ), and small ( 8 to $14 \mu \mathrm{m}$ ) RGCs in Macaca. These cells tended to form a continuum, rather than distinct size classes, as was observed in the cat or ferret. Nevertheless, in tangential sections, the largest RGCs were analyzed for uniformity in their spatial distribution. They were found to exhibit a level of regularity $(\overline{\mathrm{X}} / \mathrm{SD}=2.74$ for Saimiri and 2.92 for Macaca) similar to that observed in the cat and ferret. In the two primates, large RGCs tended to be more reactive than medium-sized RGCs, while small RGCs were a little less reactive. Morcover, a higher proportion of the large RGCs was darkly reactive, compared with medium or small RGCs. However, darkly reactive medium and small RGCs were also observed among those that were less reactive.

In transverse sections, the reactive dendrites of large, me dium, and small RGCs were found to stratify in both IPL-a and IPL-b. In Saimiri, there was little difference in the proportion of RGC dendrites that was stratified within IPL-a versus IPL-b. However, in Macaca, there was a tendency for greater numbers of RGC dendrites to be stratified in the IPL-b than in IPL-a (see Table II).

\section{CO histochemistry of the LGN}

The carnivore $L G N$. In the cat and ferret, lamina $\mathrm{A}$ and $\mathrm{C}$ receive input from the contralateral eye, while fibers from the ipsilateral eye project mainly to lamina A1 (Guillery, 1970; Sanderson, 1974). In the ferret (and mink), laminae A and AI are each subdivided into inner $(\mathrm{A}, \mathrm{A1})$ and outer $\left(\mathrm{A}^{\prime}, \mathrm{Al}^{\prime}\right)$ leaflets (Linden et al., 1981), whereas in the cat they are not. The histochemical localization of $\mathrm{CO}$ in the cat LGN has already been described at the laminar (Wong-Riley, 1979), cellular, and EM (Kageyama and Wong-Riley, 1982b) levels. Briefly, laminae $\mathrm{A}, \mathrm{A} 1$, and the magnocellular portion of $\mathrm{C}$ and the medial interlaminar nucleus were darkly reactive, while the parvocellular portion of $\mathrm{C}$ was only moderately reactive. Staining was intensified within the monocular segment of A. Large cells $(18$ to $30 \mu \mathrm{m})$ tended to be more intensely reactive than medium (13 to $17 \mu \mathrm{m})$ or small $(8$ to $12 \mu \mathrm{m})$ cells and were located within the medial interlaminar nucleus and laminae $\mathrm{A}$, A1, and magnocellular lamina $\mathrm{C}$.

In the ferret LGN, the outer $\left(\mathrm{A}^{\prime}\right.$ and $\mathrm{Al}^{\prime}$ ) leaflets of each laminae were more darkly reactive than the inner (A and $\mathrm{A} 1)$ leaflets (Fig. 4A). This pattern of staining was observed best in parasagittal and horizontal sections. The magnocellular portion of lamina $\mathrm{C}$ was also darkly reactive, while parvocellular $\mathrm{C}$ was only moderately stained. As in the cat, moderately to

\section{TABLE II}

Number and percentage of RGCs with moderately to darkly reactive dendrites projecting to IPL-a or IPL-b

The number and percentage of RGCs with moderately to darkly reactive dendrites were determined from transverse retinal sections. Only those cells with reasonably clear dendritic stratification into either IPL-a or IPL-b were counted in this analysis. Large RGCs were counted separately from those that were medium in size. $N$ represents the total number of units encountered from several retinal sections and different. animals. It is possible that at least some of the RGCs counted as IPL-b stratified cells may have actually beeen IPL-a cells with dendrites that had been cut off during sectioning.

\begin{tabular}{|c|c|c|c|c|c|c|}
\hline \multirow{2}{*}{ Species } & \multicolumn{3}{|c|}{ Large RGCs } & \multicolumn{3}{|c|}{ Medium-sized RGCs } \\
\hline & $N$ & IPL-a & IPL-b & $N$ & IPL-a & IPL-b \\
\hline Ferret & 74 & $62(83.8 \%)$ & $12(16.2 \%)$ & 148 & $145(98.0 \%)$ & $3(2.0 \%)$ \\
\hline Cat & 34 & $30(88.2 \%)$ & $4(11.8 \%)$ & 103 & $88(85.4 \%)$ & $15(14.6 \%)$ \\
\hline Saimiri & 34 & $18(52.9 \%)$ & $16(47.1 \%)$ & 161 & $99(61.5 \%)$ & $62(38.5 \%)$ \\
\hline Macaca & 69 & $28(40.6 \%)$ & $41(59.4 \%)$ & 111 & $31(27.9 \%)$ & $80(72.1 \%)$ \\
\hline
\end{tabular}


darkly reactive large cells (19 to $25 \mu \mathrm{m}$ ) were more intensely stained than the lightly reactive medium to small (8 to $18 \mu \mathrm{m})$ LGN neurons (Fig. $5, B$ and $C$ ). As in the cat, reactive large cells were distributed throughout laminae $A, A^{\prime}, A 1, A 1^{\prime}$, and magnocellular C. At the EM level, darkly reactive mitochondria were observed primarily within dendritic profiles and, to a lesser extent, the somata of large neurons.

The primate LGN. The primate LGN usually consists of six major laminae, numbered 1 to 6 ventrodorsally (for reviews, see Polyak, 1957; Hassler, 1967), and each is functionally specialized (Schiller and Malpeli, 1978). In the rhesus monkey, the laminae are distinct and separated by thin fibrous zones (Fig. 4C). However, in Saimiri, only the ventral magnocellular pair (laminae 1 and 2) are distinct (Fig. 4B); the dorsal four parvocellular laminae ( 3 to 6 ) are functionally distinct but are not segregated by fibrous zones. Their presence has been revealed by enucleation combined with transneuronal degeneration methods (Doty et al., 1966; Wong-Riley, 1972) and by anterograde labeling with horseradish peroxidase (Fitzpatrick et al., 1983). In reacted sections of primate LGN, magnocellular laminae 1 and 2 and parvocellular lamina 6 were darkly stained, while laminae 3 to 5 were moderately stained. In some sections, lamina 5 was slightly more darkly stained than laminae 3 and 4. Similarly, lamina 1 , due to its greater cellular density, often appeared more darkly stained than lamina 2 (see also WongRiley and Carroll, 1984). The medial and lateral edges of the primate LGN were consistently darker than the midregion of each lamina. Within each lamina, darkly reactive cells were observed. They were larger and more numerous (80 to $90 \%$ ) within magnocellular laminae 1 and 2 than in the parvocellular laminae (see Fig. $5 D$ ). Lamina 6 also contained a high proportion ( 70 to $90 \%$ ) of darkly reactive cells, but they were medium in size. In laminae 3,4 , and 5 , the proportion of darkly reactive cells was much lower (45 to $55 \%$ ).

In addition to the six primary laminae of the primate LGN, intercalated laminae (interlaminar zones) consisting primarily of small cells (LeGros-Clark, 1941; Guillery and Colonnier, 1970; Fitzpatrick et al., 1983; Weber et al., 1983) and an S layer consisting of large and small cells (Fitzpatrick et al., 1983) have also been described. In the present study, most $(80 \%)$ of the small intercalated cells and S layer cells were only lightly stained for $\mathrm{CO}$, while some of the larger cells in layer $\mathrm{S}$ were moderately to darkly stained.

Overall, a higher proportion of the large magnocellular cells (presumed Y-like) were more darkly stained than the parvocellular cells (presumed X-like), while the small intercalated cells and $S$ layer cells (presumed W-like) tended to be only lightly reactive. Within each of the major laminae, the darker reactive cells were generally larger than the moderately to lightly stained cells.

\section{Discussion}

\section{The laminar and cellular distribution of $\mathrm{CO}$ in the retina}

The laminar pattern of $\mathrm{CO}$ staining in the retina is consistent with previous descriptions of the distribution of oxidative enzymes in the retina (Wislocki and Sidman, 1954; Strominger and Lowry, 1955; Lowry et al., 1956; Niemi and Merenmies, 1961). These studies have generally reported high enzyme levels in the photoreceptor inner segments and the plexiform layers.

Photoreceptors. The contrast between the darkly reactive photoreceptor inner segments and cone pedicles, on the one hand, and the lightly reactive photoreceptor outer segments and cell bodies (ONL), on the other, implies that different parts of the same cell may exhibit different levels of CO activity.

The intense staining of inner segments correlates with the localization of the $\left[{ }^{3} \mathrm{H}\right]$ ouabain-labeled $\mathrm{Na}^{+} / \mathrm{K}^{+}$-ATPase (sodium pump) and the site of the $\mathrm{KCN}$ - and ouabain-sensitive “dark current" (Penn and Hagins, 1969; Yoshikami and Hagins, 1970; Zuckerman, 1971, 1972; Bok and Filerman, 1979; Stirling and Lee, 1980), suggesting that a large portion of the energy derived from oxidative metabolism may be utilized for the maintenance of ionic gradients. The amount of energy required by photoreceptors must be considerable since these cells are tonically depolarized in the absence of light.

The selective dark staining of the large mitochondria in cone pedicles, in contrast to the light staining of the smaller and less frequently observed mitochondria within rod spherules, implies that there is a fundamental difference between rods and cones in the localization of oxidative energy metabolism.

Horizontal cells. The dark staining of the primary horizontal cell processes and somata located within the inner OPL and outer INL is evidence that these cells are metabolically quite active. It is known that horizontal cells form specialized contacts with a large number of cone pedicles (Kolb, 1977), but it is not clear how this convergence may relate to the metabolic activity of these cells. It is unlikely that their intense staining is related to spike activity, because these cells are not known to generate action potentials.

Bipolar cells. The moderate to dark staining of smaller, more vertically oriented cells in the outer half of the INL suggests that many bipolar cells are also metabolically very active. However, the moderate to light staining of (presumed) bipolar cells in the middle to inner INL implies that bipolar cells form a heterogeneous class and that some classes may be more active than others. Different classes of bipolar cells have been described from Golgi preparations (Polyak, 1941, 1957), and many of these correspond to physiologically distinct types (for review, see Sterling, 1983).

In the IPL, the reactive mitochondria observed within bipolar axon terminals of the ferret may be the correlate of some of the darkly reactive punctate structures observed within the IPL of ferret, cat, and monkey at the light microscopic level.

Amacrine cells. Although amacrine somata are characterized by a sparse distribution of lightly reactive mitochondria, the distal amacrine cell processes (in IPL) may exhibit a level of oxidative enzyme staining that is moderate to dark. A similar pattern of CO localization was observed in LGN interneurons, which have presynaptic dendrites (Kageyama and Wong-Riley, $1982 b)$. The distal dendritic localization of intense CO staining has also been described for several classes of hippocampal neurons (Kageyama and Wong-Riley, 1982a). The dark staining of these distal dendritic segments coincides with known sites of potent excitatory input. This pattern of staining is consistent with the hypothesis that peripheral processes of neurons may serve as functionally segregated active components of a neural circuit (Ralston, 1976; Miller, 1979) or simply as distal sites of intense synaptic interaction (Kageyama and Wong-Riley, 1982a).

Although distinct types of amacrine cells have been described (for review, see Sterling, 1983), we have found little evidence for major differences in their pattern of staining in the species examined. However, differences may exist with respect to the intensity of staining within their processes, since at the light microscopic level there are significant staining differences between IPL-a and IPL-b, the termination sites for amacrine processes.

$R G C s$. The presence of moderate to dark staining within RGC dendrites indicates that dendrites contribute to the overall intensity of staining within the IPL. The moderate to dark staining within most RGC somata may be accounted for by their moderate to high tonic maintained discharge rates (Stone and Fukuda, 1974; Bullier and Norton, 1979) even in darkness (Kuffler et al., 1957), while the lighter staining in the small (presumed W) RGCs of the cat (and presumably ferret) is consistent with their relatively low discharge rates. 

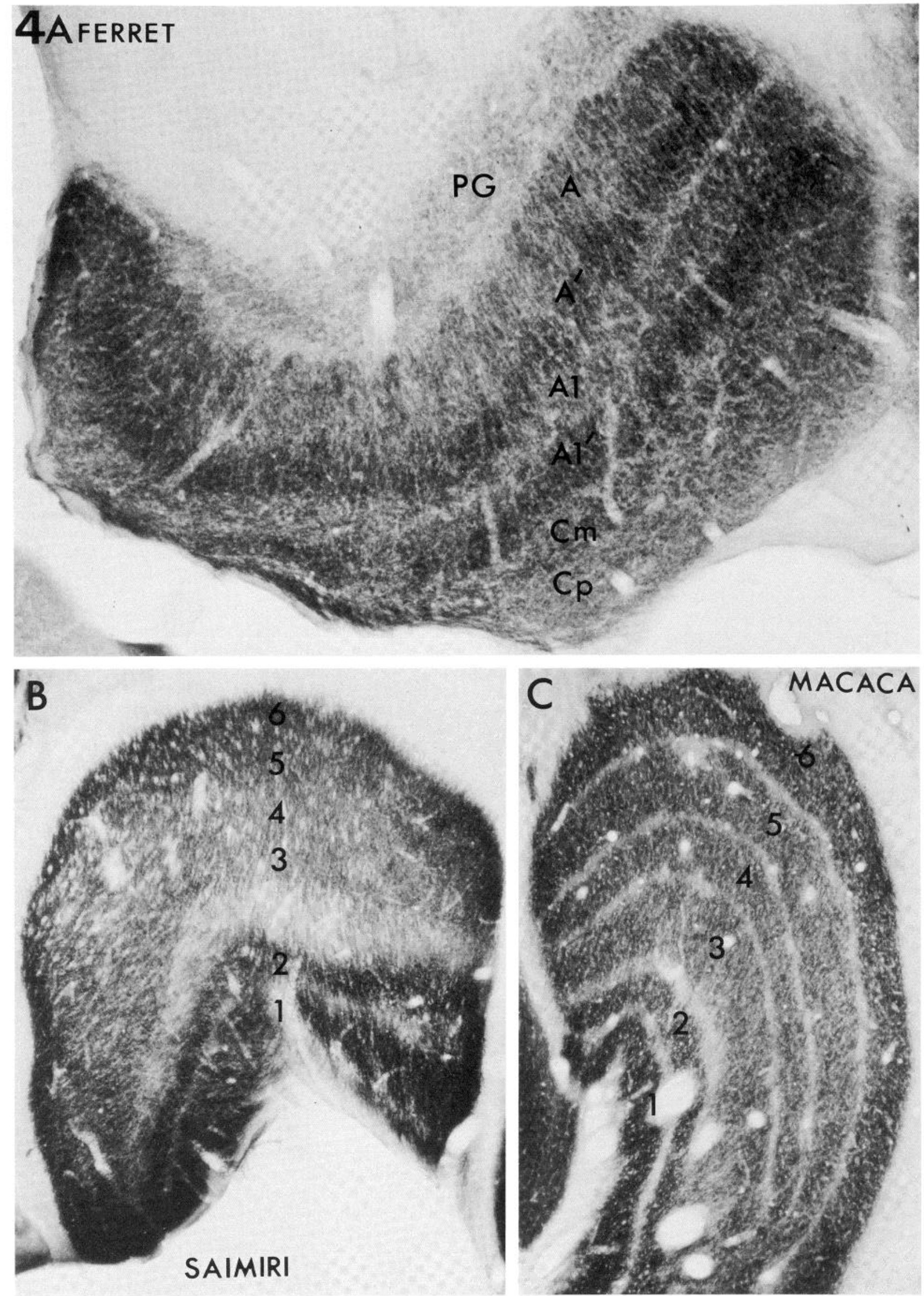
Ganglion cell axons. The darkly reactive unmyelinated and lightly reactive myelinated segments of $R G C$ axons are an example of oxidative enzymatic differences between two segments of the same axon. The energy demands for axoplasmic transport cannot account for staining differences between the myelinated and unmyelinated axon segments, because it is presumably the same within both segments. One possibility is that unmyelinated axons or axonal segments may require more energy to repolarize a greater portion of their total membrane surface compared with myelinated axons.

\section{CO histochemistry of retinal mosaics}

Applying CO histochemistry to tangential sections of retina, we were able to demonstrate not only that very specific retinal components are uniformly darkly or moderately reactive, but also that they exhibit a notable degree of regularity in their spatial distribution. Each of the retinal components measured (Table I) met the requirements of quantitative staining and clear morphological recognition for such an analysis (Wässle and Riemann, 1978). The retinal mosaics examined demonstrated that (1) the nearest neighbor distributions were Gaussian and not skewed to the left (i.e., not random), (2) most $\overline{\mathrm{X}}$ / $\mathrm{SD}$ ratios were relatively high, and all were comparable to the $\overline{\mathrm{X}} / \mathrm{SD}$ values of retinal mosaics stained by other methods (Wässle and Riemann, 1978; Wässle et al., 1978, 1981b), (3) mosaics closer to area centralis (or fovea) were more precisely arrayed than peripheral mosaics, (4) units closer to area centralis (or fovea) of each mosaic were consistently smaller and more densely packed than peripheral units, (5) mosaics located in the outer retina (e.g., cone inner segments, cone pedicles, and horizontal cells) tended to be more regularly arrayed than mosaics located in the inner retina (e.g., RGCs), and (6) primate photoreceptor mosaics tended to be more regularly arrayed than those of carnivores.

Photoreceptor mosaics. The regularity in the distribution of cone inner segments has been described for both rhesus monkey and cat in Azan-stained retinal whole mounts (Wässle and Riemann, 1978). To these data we may now add that cone inner segments of squirrel monkey and ferret are also regularly arrayed and that in all species they are darkly reactive for $\mathrm{CO}$. In each species, the corresponding cone pedicles are distributed with a similar degree of precision as cone inner segments. It is assumed that the greater degree of precision of cone distribution in the primate contributes to their greater visual acuity. The finding that cone pedicles are darkly reactive but rod spherules are not implies that there is a fundamental metabolic difference between rods and cones.

Horizontal cell mosaic. Two types of horizontal cells have already been shown to be regularly arrayed in the cat (Wässle and Riemann, 1978; Wässle et al., 1981b). This study provides evidence that one type of horizontal cell in the rhesus monkey is also regularly arrayed $(\overline{\mathrm{X}} / \mathrm{SD}=6.52$, peripheral retina) and darkly reactive for $\mathrm{CO}$. The high degree of regularity of the rhesus monkey horizontal cell array is consistent with the claim that primates have only one type of horizontal cell (Polyak, 1941; Kolb, 1970; Gallego, 1971; Boycott and Kolb, 1973).
$R G C$ mosaics. Large RGCs exhibited a similar degree of regularity in all species examined, and it is comparable to the level of regularity $(\overline{\mathrm{X}} / \mathrm{SD})$ reported for Nissl-stained $\alpha$ cells in the cat (Wässle and Riemann, 1978). In the ferret and cat, the two metabolic subclasses of $\alpha$ cells, one dark and the other modcrately reactive, appear to represent predominantly OFF and $\mathrm{ON}-\alpha$ cells, respectively. This conclusion is based on several observations. First, darkly and moderately reactive $\alpha$ cells form two independent, regularly arrayed mosaics, with $\overline{\mathrm{X}} / \mathrm{SD}$ values comparable to those obtained for the two neurofibrillarstained OFF- and $\mathrm{ON}-\alpha$ cell populations described in the cat (Wässle et al., 1981b). Second, in transverse sections, the reactive dendrites of the darkly reactive large RGCs are predominantly stratified within the IPL-a, which characterizes OFF-RGCs (Famiglietti and Kolb, 1976; Nelson et al., 1978). Third, nearest neighbor pairs of $\alpha$ cells usually exhibited a different level of oxidative enzyme staining, one being darker than the other.

As with the large $\mathrm{RGCs}$, it seemed possible that the darkly and moderately reactive medium-sized (presumed $\beta$ ) RGCs in the cat and ferret may represent $O F F-$ and $O N-\beta$ cells, since they occurred with nearly equal frequency. However, it was clear from visual inspection that the dark and moderately stained populations of medium-sized RGCs were not as precisely arrayed $(\overline{\mathrm{X}} / \mathrm{SD}=3.38)$ as was reported for $\mathrm{ON}-(\overline{\mathrm{X}} / \mathrm{SD}$ $=5.29)$ and $\mathrm{OFF}-(\overline{\mathrm{X}} / \mathrm{SD}=5.31) \beta$ cells (Wässle et al., 1981a) In tangential sections of ferret retina, the observation that many of the darkly reactive medium-sized cells possess a single darkly reactive apical dendrite, and the finding that these reactive dendrites form a very regular mosaic array $(\overline{\mathrm{X}} / \mathrm{SD}=$ 6.05 ), strongly suggests that they belong to a very specific class of RGCs. Further evidence for this is that this cell type very closely resembles the OFF- $\beta$ (OFF-X, IIa) RGC of the cat, with respect to its size, distribution (density and regularity), morphology, and fine structure (Boycott and Wässle, 1974; Famiglietti and Kolb, 1976; Nelson et al., 1978; Wässle et al., 1981a; Sterling, 1983). The resemblance perhaps is clearly seen in transverse sections (Fig. $3 D$ ). Thus, while these cells with darkly reactive dendrites probably represent OFF- $\beta$ RGCs, the other darkly and moderately reactive medium-sized RGCs probably represent $O N-\beta$ and other types of RGCs. Our results indicate that, while not all darkly reactive medium-sized $R G C s$ are OFF- $\beta$ cells, those with darkly reactive dendrites probably are.

In the primate retina, only the large darkly reactive RGCs formed a distinguishable regularly arrayed mosaic. Since the medium-sized and small RGCs did not form either distinct size or metabolic subclasses, they were not analyzed for regularity in their spatial distribution. In these ways, the pattern of primate RGC staining differed significantly from the cat and ferret.

\section{$O N$ - and OFF-visual channels}

In the cat and ferret, differences in the staining between the $\mathrm{ON}$ - and OFF-sublaminae of the IPL and between presumed $\mathrm{ON}$ - and OFF-RGCs may be related to the differences in

Figure 4. $A$ to $C$, The distribution of $C O$ within $O N$ - and OFF-center laminae within the carnivore and primate LGN. $A$, Parasagittal section of ferret LGN. Laminae $A$ and $A 1$ in the ferret are subdivided into inner ( $A$ and $A 1)$ and outer $\left(A^{\prime}\right.$ and $\left.A 1^{\prime}\right)$ leaflets. Up is anterior and left is dorsal. Note the greater intensity of staining within the outer leaflets $A^{\prime}$ and $A 1^{\prime}$ compared with the inner leaflets $A$ and $A 1$. Magnocellular lamina $\mathrm{C}(\mathrm{Cm})$ also exhibits greater staining than parvocellular laminae $\mathrm{C}(\mathrm{Cp})$, while the perigeniculate nucleus $(P G)$ appears to be only lightly stained. Moderately dark reactive large cells were distributed throughout all of the A laminae and magnocellular lamina C. Cells in pigment epithelium were moderately stained. Magnification $\times 73$. $B$, Coronal section of squirrel monkey LGN. The magnocellular laminae 1 and 2 are darkly stained, while the staining intensity within the parvocellular zone ( 3 to 6 ) varies from moderate to dark. The numbers 3 to 6 are used to designate the approximate location of the hidden parvocellular laminae in the squirrel monkey LGN that may be homologous to the parvocellular laminae 3 to 6 in the macaque LGN. In this figure, the dorsal parvocellular zone (5 and 6$)$ is more darkly stained than the ventral parvocellular zone ( 3 and 4). Magnification $\times 36$. C, Coronal section of macaque monkey LGN. The pattern of staining in the macaque LGN is similar to that in the squirrel monkey. The magnocellular laminae 1 and 2 are darkly stained, as is parvocellular lamina 6 . The remaining laminae 3 to 5 are only moderately stained. Magnification $\times 28$. 

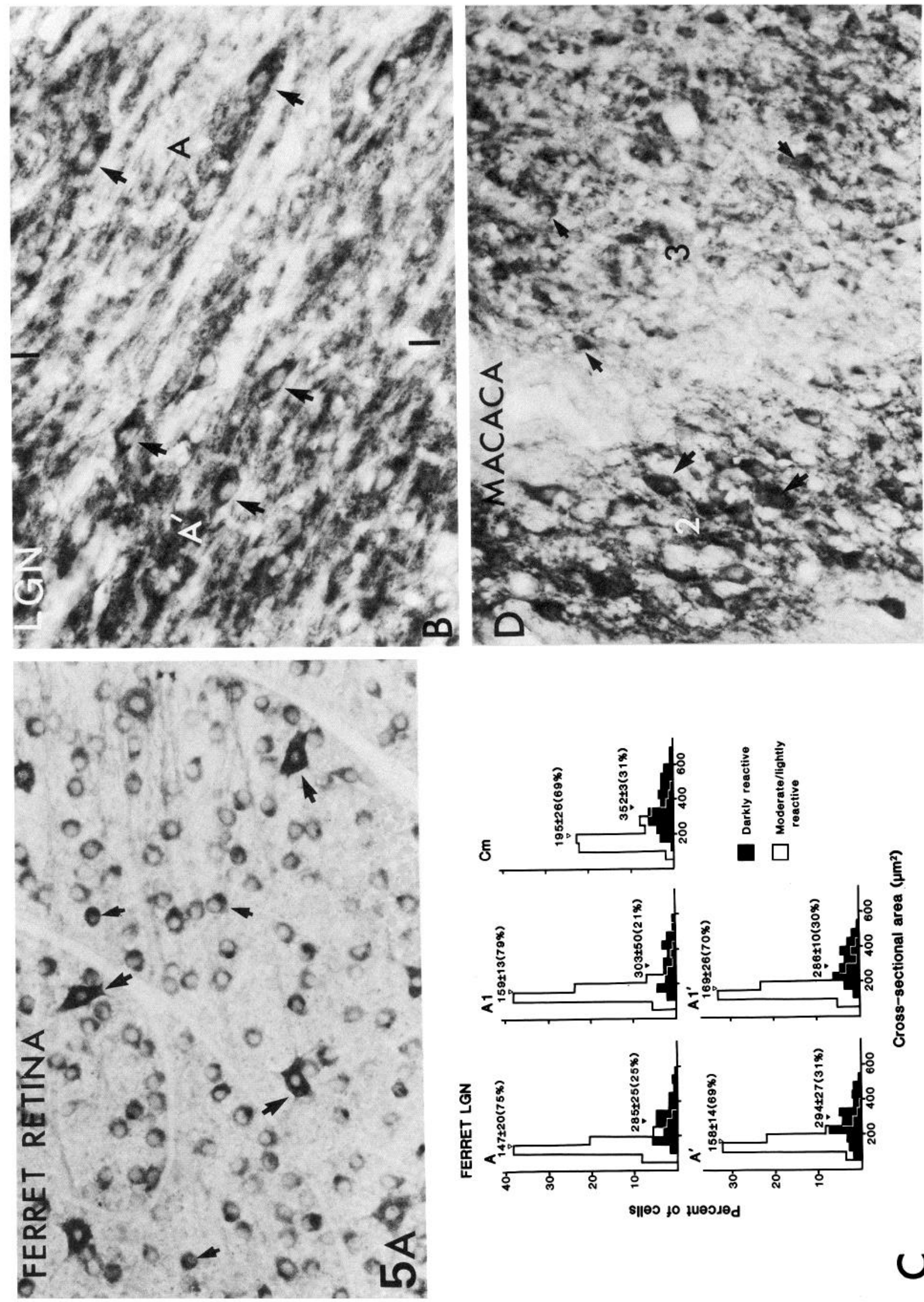
maintained discharge rates exhibited by these cells under varying conditions of light adaptation. For example, OFF-center cells have higher maintained discharge rates under conditions of low luminance, but their rates decrease with increased luminance. This relationship is reversed for ON-center cells, which are more active at higher luminance levels (Barlow and Levick, 1969; Frishman and Levine, 1983). The metabolic responses of ON- and OFF-channels to the level of light adaptation correlates with the physiological response levels and has recently been demonstrated using the 2-deoxyglucose technique in the visual system of the ferret (Stryker and Zahs, 1983b) Stryker and Zahs' finding that the ON-LGN sublaminae selectively take up more 2-deoxyglucose under conditions of bright illumination, is in general agreement with the physiological data cited above. Unfortunately, our findings cannot be directly correlated with possible physiological differences between $\mathrm{ON}$ and OFF-channel activity in the ferret and cat, because the luminance conditions were not controlled nor was the physiological activity of RGCs monitored. However, based on Stryker and Zahs' findings, we can suggest that the darker staining of the OFF-channel in the cat and ferret may possibly be due to a relatively greater exposure of the animals to low luminance conditions. Since the cats and primates were housed with the same 12-hr light-dark cycle, however, the differences in staining patterns between these species cannot readily be explained on the basis of lighting conditions alone. Thus, whether these differences result from intrinsic neuronal properties or neuronal responses to lighting conditions remains to be determined.

In primates, the darker staining of IPL-b, compared with IPL-a in the primate retina, is consistent with the darker staining in LGN lamina 6 and (sometimes) 5 (ON-) compared with laminae 3 and 4 (OFF-) and suggests that some neuronal components of the ON-channel may be metabolically more active than the OFF-channel in primates. However, this interpretation is complicated by several facts. First, ON- and OFFcenter units are not as distinctly segregated in the primate as they are in the ferret (and mink). Second, color appears to play a more important role in primate visual processing and may have an important influence on the pattern of staining. Third, the lack of consistently darker staining of lamina 5 compared with either laminae 3 or 4 suggests that factors other than ONand OFF-channel differences may also be involved in the overall pattern of $\mathrm{CO}$ staining in the primate LGN. Lastly, in the primate retina, darkly reactive $\mathrm{RGC}$ dendrites were stratified within either IPL-a or IPL-b, implying that elements of both $\mathrm{ON}$ - and OFF-pathways are quite active.

\section{$X, Y$, and $W$ pathways}

We also observed differences in the level of $\mathrm{CO}$ staining within the neuronal components of the $\mathrm{X}, \mathrm{Y}$, and $\mathrm{W}$ pathways. While the differences between $\mathrm{ON}$ - and OFF-channels were most clearly discerned in the neuropil of the IPL and LGN sublaminae and the somata of cat and ferret RGCs, differences between the $\mathrm{X}, \mathrm{Y}$, and $\mathrm{W}$ pathways were most apparent in the neuronal cell bodies of the LGN. In the LGN of all species examined, the darker staining of predominantly large (presumed Y/Y-like) cells compared with the medium-sized (presumed X/X-like) cells and medium to small (presumed W/Wlike and interneurons) cells implies that the geniculate $\mathrm{Y}$-cells are relatively more active than the other neuron types. Similar findings in the cat LGN have been reported (Kageyama and Wong-Riley, 1982b). The greater intensity of staining within the large, presumed Y-cells in the cat LGN may be related to their relatively higher maintained discharge rates (Wilson et al., 1976; Bullier and Norton, 1979). Since cell size is not necessarily related to greater staining (e.g., Purkinje cells and CA1 pyramidal cells are only lightly reactive; Wong-Riley, 1976; Kageyama and Wong-Riley, 1982a), the larger cytoplasmic volume and more extensive axonal arborization in $\mathrm{Y}$ cells (LeVay and Ferster, 1977; Ferster and LeVay, 1978; Friedlander et al., 1981) do not provide an adequate explanation for their darker staining. On the other hand, the lighter staining in geniculate $\mathrm{X}$ cells may be related to stronger inhibitory influences upon these cells (Fukuda and Stone, 1976; Bullier and Norton, 1979). Whatever the cause for the differences in CO staining amongst the various populations of geniculate neurons, our results indicate that distinct neuronal populations tend to exhibit characteristic patterns of $\mathrm{CO}$ staining under relatively normal rearing conditions. The dark staining of the large cells of the ferret LGN and the magnocellular neurons of the primate LGN reflects a basic metabolic similarity of these cells to $\mathrm{Y}$ cells in the cat (Dreher et al., 1976; Schiller and Malpeli, 1978).

Thus, while different oxidative metabolic levels may exist within the ON- and OFF-channels in the retina and in the neuropil of the LGN, the functional differences between the X and $\mathrm{Y}$ systems may account, in part, for the staining differences observed between the presumed $\mathrm{X}$ and $\mathrm{Y}$ cell bodies at the LGN level. The light staining of the presumed $W$ cells, on the other hand, may be related to their sluggish response properties and low maintained discharge rates at both the retinal and LGN levels (Stone and Fukuda, 1974; Wilson et al., 1976).

\section{Conclusions}

This study demonstrates several important features about the histochemical localization of CO in the retina and LGN of the cat, ferret, and monkey. (1) In the retina, the intensity of oxidative enzyme staining may differ markedly between distinct laminae, cell types, and/or parts (or segments) of individual cells. (2) Several darkly reactive cell types and/or parts of cells form precisely arrayed retinal mosaics. (3) Differences in the pattern of $\mathrm{CO}$ staining exist between carnivores and primates in the ON- and OFF - sublaminae of the retinal IPL and within corresponding ON-and OFF- laminae in the LGN. (4) The

Figure 5. A to D, The localization of dark CO staining within large (presumed Y/Y-like) cells of the carnivore and primate retina and LGN. $A$, Tangential section of the ganglion cell layer of the ferret retina. Darkly reactive large (presumed $\alpha$ ) and medium-sized RGCs are indicated by large and small arrows, respectively. Note that about half of the medium-sized RGCs and a few large RGCs are moderately stained, while the smallest RGCs are only lightly stained. Magnification $\times 229$. B. High magnification of the ferret LGN showing a portion of sublaminae A (ON-) and $\mathrm{A}^{\prime}\left(\mathrm{OFF}\right.$-). Arrows point to darkly reactive large (presumed $\mathrm{Y} / \mathrm{Y}$-like) LGN neurons. Note that there arc more of these cells in $\mathrm{A}^{\prime}$ than in A. The more frequently observed medium and small LGN neurons are distributed throughout the field but are not easily discerned when viewed through a dark blue (Wratten no. 47) filter, because they lack dense accumulations of reaction product. Their presence is easily demonstrated in Nissl-counterstained sections. Magnification $\times 286$. C, Histograms showing the percentage distribution of darkly reactive and moderate/lightly reactive LGN neurons by cell size (cross-sectional area, square micrometers) from the ferret LGN. Each histogram represent a total of 300 cells, 100 cells measured from each of three ferrets, for each of the major laminae. Note that the cells are notably larger in magnocellular laminae $\mathrm{C}$ $(\mathrm{Cm})$ than in the other laminae. Note also that while there are a few darkly reactive medium and small LGN neurons and a few moderate/lightly reactive large neurons, most of the darkly reactive neurons are large. $D$, High magnification of a small area of the macaque LGN, showing the distribution of darkly reactive LGN neurons within magnocellular lamina $2(2)$ and parvocellular laminae $3(3)$. Note that the darkly reactive cells are larger and more numerous within magnocellular lamina 2 (large arrows) compared with parvocellular lamina 3 (small arrows). Magnification $\times 183$ 
most intensely stained RGCs and LGN neurons tend to be the large, presumed $\mathrm{Y}, \mathrm{Y}$-like cells in all species examined. (5) A significant portion of the dark $\mathrm{CO}$ staining in the retina and LGN is localized at known sites of synaptic interaction (i.e., OPL and IPL of retina and neuropil of LGN).

\section{References}

Bok, D., and B. Filerman (1979) Autoradiographic localization of $\mathrm{Na}^{+}$. $\mathrm{K}^{+}$ATPase in retinal photoreceptors and RPE with $\left[{ }^{3} \mathrm{H}\right]$-ouabain. Invest. Ophthalmol. Vis. Sci. Suppl. 18: 224.

Barlow, H. B., and W. R. Levick (1969) Changes in maintained discharge with adaptation level in the cat retina. J. Physiol (Lond.) 202: $699-718$.

Boycott, B. B., and H. Kolb (1973) The connections between bipolar cells and photoreceptors in the retina of the domestic cat. J. Comp. Neurol. 148: 91-114.

Boycott, B. B., and H. Wässle (1974) The morphological types of ganglion cells of the domestic cat's retina. J. Physiol. (Lond.) 240. $397-419$.

Bullier, J., and T. T. Norton (1979) Comparison of receptive field properties of $\mathrm{X}$ and $\mathrm{Y}$ ganglion cells with $\mathrm{X}$ and $\mathrm{Y}$ lateral geniculate cells in the cat. J. Neurophysiol. 42: 274-291.

Cleland, B. G., M. W. Dubin, and W. R. Levick (1971) Sustained and transient neurons in the cat's retina and lateral geniculate nucleus. J. Physiol. (Lond.) 273: 473-496.

Conway, J., P. H. Schiller, and L. Mistler (1980) Functional organization of the tree shrew lateral geniculate nucleus. Soc. Neurosci. Abstr. 6: 583.

Doty, R. W., M. Glickstein, and W. H. Calvin (1966) Lamination of the lateral geniculate nucleus of the squirrel monkey, Saimiri sciureus. J. Comp. Neurol. 127: 335-340.

Dreher, B., Y. Fukada, and R. W. Rodieck (1976) Identification, classification and anatomical segregation of cells with X-like and Y-like properties in the lateral geniculate nucleus of Old-World primates. J. Physiol. (Lond.) 258: 433-452.

Enroth-Cugell, C., and J. G. Robson (1966) The contrast sensitivity of retinal ganglion cells of the cat. J. Physiol. (Lond.) 187: 517-552.

Famiglietti, E. V., Jr. and H. Kolb (1976) Structural basis for ON- and OFF-center responses in retinal ganglion cells. Science 194: 193-195.

Ferster, D., and S. LeVay (1978) The axonal arborizations of the lateral geniculate neurons in the striate cortex of the cat. J. Comp. Neurol. 182: 923-944.

Fitzpatrick, D., K. Itoh, and I. T. Diamond (1983) The laminar organization of the lateral geniculate body and the striate cortex in the squirrel monkey (Saimiri sciureus). J. Neurosci. 3: 673-702.

Friedlander, M. J., C.-S. Lin, L. R. Stanford, and S. M. Sherman (1981) Morphology of functionally identified neurons in the lateral geniculate nucleus of the cat. J. Neurophysiol. 46: 80-129.

Frishman, L. J., and M. W. Levine (1983) Statistics of the maintained discharge of cat retinal ganglion cells. J. Physiol. (Lond.) 339: 475494.

Fukuda, Y., and J. Stone (1976) Evidence of differential inhibitory influences on $\mathrm{X}$ - and $\mathrm{Y}$-type relay cells in the cat's lateral geniculate nucleus. Brain Res. 113: 188-196.

Gallego, A. (1971) Horizontal and amacrine cells in the mammal's retina. Vision Res. 3: 33-50.

Guillery, R. W. (1966) A study of Golgi preparations from the dorsal lateral geniculate nucleus of the adult cat. J. Comp. Neurol. 128: 2150.

Guillery, R. W. (1970) The laminar distribution of retinal fibers in the dorsal lateral geniculate nucleus of the cat: A new interpretation. .J. Comp. Neurol. 138: 339-368.

Guillery, R. W., and M. Colonnier (1970) Synaptic patterns in the dorsal lateral geniculate nucleus of the monkey. Z. Zellforsch. 103: 90-108.

Hassler, R. (1967) Comparative anatomy of the central visual systems in day- and night-active primates. In Evolution of the Forebrain, Phylogenesis and Ontogenesis of the Forebrain, $\mathrm{R}$. Hassler and $\mathrm{H}$. Stephan, eds., pp. 419-434, Plenum Press, New York.

Hubel, D. H., and M. S. Livingstone (1981) Regions of poor orientation tuning coincide with patches of cytochrome oxidase staining in monkey striate cortex. Soc. Neurosci. Abstr. 7: 357.

Itoh, K., M. Conley, and I. T. Diamond (1982) Retinal ganglion ceil projections to individual layers of the lateral geniculate body in Galago crassicaudatus. J. Comp. Neurol. 205: 282-290.
Kageyama, G. H., and M. Wong-Riley (1982a) Histochemical localization of cytochrome oxidase in the hippocampus: Correlation with specific neuronal types and afferent pathways. Neuroscience 7:23372361.

Kageyama, G. H., and M. Wong-Riley (1982b) Light and E. M. localization of cytochrome oxidase staining in the lateral geniculate nucleus. Soc. Neurosci. Abstr. 8: 208.

Kageyama, G. H., and M. Wong-Riley (1983) Differential cytochrome oxidase staining of OFF- and ON-center visual channels in retina and lateral geniculate nucleus of ferret and monkey. Soc. Neurosci. Abstr. 9: 814.

Kolb, H. (1970) Organization of the outer plexiform layer of the primate retina: Electron microscopy of Golgi-impregnated cells. Philos. Trans. R. Soc. Lond. Biol. 258: 261-283.

Kolb, H. (1977) The organization of the outer plexiform layer in the retina of the cat: Electron microscopic observations. J. Neurocytol. 6: 131-153.

Kuffler, S. W, R. Fitzhugh, and H. B. Barlow (1957) Maintained activity in the cat's retina in light and darkness. J. Gen. Physiol. 40 $683-702$

LeGros Clark, W. E. (1941) The lateral geniculate body in the platyrrhine monkeys. J. Anat. 76: 131-140.

LeVay, S., and D. Ferster (1977) Relay cell classes in the lateral geniculate nucleus of the cat and the effects of visual deprivation. J. Comp. Neurol. 172: 563-584.

LeVay, S., and S. K. McConnell (1982) ON and OFF layers in the lateral geniculate nucleus of the mink. Nature 300:350-351.

Leventhal, A. G., R. W. Rodieck, and B. Dreher (1981) Retinal ganglion cell classes in the Old World monkey: Morphology and central projections. Science 213: 1139-1142.

Linden, D. C., R. W. Guillery, and J. Cucchiaro (1981) The dorsal lateral geniculate nucleus of the normal ferret and its postnatal development. J. Comp. Neurol. 203: 189-211.

Lowry, O. H., N. R. Roberts, and C. Lewis (1956) The quantitative histochemistry of the retina. J. Biol. Chem. 220: 879892.

Miller, R. F. (1979) The neuronal basis of ganglion-cell receptive-field organization and the physiology of amacrine cells. In Neurosciences: Fourth Study Program, F. O. Schmidt and F. G. Worden, eds., pp. 227-245, MIT Press, Cambridge, MA.

Nelson, R., E. V. Famiglietti, Jr., and H. Kolb (1978) Intracellular staining reveals different levels of stratification for $\mathrm{ON}$ - and $\mathrm{OFF}^{-}$ center ganglion cells in cat retina. J. Neurophysiol. 41: 472-483.

Niemi, M., and E. Merenmies (1961) Cytochemical localization of the oxidative enzyme systems in the retina. II. Cytochrome oxidase. J. Neurochem. 6: 206-209.

Peichl, L., and H. Wässle (1981) Morphological identification of ONand OFF-centre briske transient (Y) cells in the cat retina. Proc. $R$ Soc. Lond. Biol. 212: 139-156.

Penn, R. D., and W. A. Hagins (1969) Signal transmission along retinal rods and the origin of the electroretinograpic a-wave. Nature 223 201-205.

Polyak, S. L. (1941) The Retina, University of Chicago Press, Chicago. Polyak, S. L. (1957) The Vertebrate Visual System, University of Chicago Press, Chicago.

Ralston, H. J., III (1976) Evidence for presynaptic dendrites and a proposal for their mechanism of action. Nature 230: 585-587.

Sanderson, K. J. (1974) Lamination of the dorsal lateral geniculate nucleus in carnivores of the weasel (Mustelidae), raccoon (Procyonidae) and fox (Canidae) families. J. Comp. Neurol. 153: 239-266.

Schiller, P. H., and J. G. Malpeli (1977) Properties and tectal projections of monkey retinal ganglion cells. J. Neurophysiol. 40:428-445.

Schiller, P. H., and J. G. Malpeli (1978) Functional specificity of lateral geniculate nucleus laminae of the rhesus monkey. J. Neurophysiol. 41: 788-797.

Stanford, L. R., M. J. Friedlander, and S. M. Sherman (1981) Morphology of physiologically identified W-cells in the C-laminae of the cat's lateral geniculate nucleus. J. Neurosci. 1: 578-584.

Sterling, P. (1983) Microcircuitry of the cat retina. Annu. Rev. Neurosci. 6: 149-185.

Stevens, J. K., B. A. McGuire, and P. Sterling (1980) Toward a functional architecture of the retina: Serial reconstruction of adjacent ganglion cells. Science 207: 317-319.

Stirling, C. E., and A. Lee $(1980)\left[{ }^{3} \mathrm{H}\right]$-Ouabain autoradiography of frog retina. J. Cell. Biol. 85: 313-324.

Stone, J., and Y. Fukuda (1974) Properties of cat retinal ganglion cells: A comparison of W-cells with X-and Y-cells. J. Physiol. (Lond.) 37: $722-748$ 
Stone, J., and K.-P. Hoffman (1972) Very slow conducting ganglion cells in the cat's retina: A major new functional type? Brain Res. 43: $610-616$.

Strominger, J. L., and O. H. Lowry (1955) The quantitative histochemistry of the brain. IV. Latic, malic and glutamic dehydrogenases. J. Biol. Chem. 213: 635-646.

Stryker, M. P., and K. R. Zahs (1983a) ON and OFF sublaminae in the lateral geniculate nucleus of the ferret. J. Neurosci. 3: 1943-1951.

Stryker, M. P., and K. R. Zahs (1983b) ON and OFF sublaminae in the lateral geniculate nucleus of the ferret. Invest. Ophthalmol. Vis. Sci. Suppl. 24: 265.

Wässle, H., and H. J. Riemann (1978) The mosaic of nerve cells in the mammalian retina. Proc. R. Soc. Lond. Biol. 200: 441-461.

Wässle, H., L. Peichl, and B. B. Boycott (1978) Topography of horizontal cells in the retina of the domestic cat. Proc. R. Soc. Lond. Biol. 203: 269-291.

Wässle, H., B. B. Boycott, and R. B. Illing (1981a) Morphology and mosaic of ON- and OFF-beta cells in the cat retina and some functional considerations. Proc. R. Soc. Lond. Biol. 212: 177-195.

Wässle, H., L. Peichl, and B. B. Boycott (1981b) Morphology and topography of On-and OFF-alpha cells in the cat retina. Proc. $R$. Soc. Lond. Biol. 212: 157-175.

Weber, J. T., M. F. Huerta, J. H. Kaas, and J. K. Harting (1983) The projections of the lateral geniculate nucleus of the squirrel monkey: Studies of the interlaminar zones and the S layers. J. Comp. Neurol. 213: $135-145$

Wilson, P. D., M. H. Rowe, and J. Stone (1976) Properties of relay cells in cat's lateral geniculate nucleus: A comparison of W-cells and $\mathrm{X}$ - and Y-cells. J. Neurophysiol. 39: 1193-1209.

Wislocki, G. B., and R. L. Sidman (1954) The chemical morphology of the retina. J. Comp. Neurol. 101: 53-99.

Wong-Riley, M. T. T. (1972) Terminal degeneration and glial reactions in the lateral geniculate nucleus of the squirrel monkey after eye removal. J. Comp. Neurol. 144: 61-92.

Wong-Riley, M. T. T. (1976) Endogenous peroxidatic activity in brainstem neurons as demonstrated by their staining with diaminobenzidine in normal squirrel monkeys. Brain Res. 108: 257-277.

Wong-Riley, M. (1979) Changes in the visual system of monocularly sutured or enucleated cats demonstrable with cytochrome oxidase histochemistry. Brain Res. 171: 11-28.

Wong-Riley, M., and E. Carroll (1984) Effect of impulse blockage on cytochrome oxidase activity in monkey visual system. Nature 307 : 262-264.

Wong-Riley, M. T. T., and D. A. Riley (1983) The effect of impulse blockage on cytochrome oxidase activity in the cat visual system. Brain Res. 261: 185-193.

Wong-Riley, M. T. T., and C. Welt (1980) Histochemical changes in cytochrome oxidase of cortical barrels after vibrissal removal in neonatal and adult mice. Proc. Natl. Acad. Sci. (U. S. A.) 77: 23332337.

Wong-Riley, M. T. T., M. M. Merzenich, and P. A. Leake (1978) Changes in endogenous enzymatic reactivity to $\mathrm{DAB}$ induced by neuronal inactivity. Brain Res. 141: 185-192.

Wong-Riley, M. T. T., P. A. Leake-Jones, S. M. Walsh, and M. M. Merzenich (1981) Maintenance of neuronal activity by electrical stimulation of unilaterally deafened cats demonstrable with cytochrome oxidase technique. Ann. Otol. Rhinol. Laryngol. 90 (Suppl. 82): $30-32$.

Yoshikami, S., and W. A. Hagins (1970) Ionic basis of dark current and photocurrent of retinal rods. Biophys. Soc. Abstr. 10: 60a.

Zuckerman, R. (1971) Mechanisms of photoreceptor current generation in light and darkness. Nature New Biol. 234: 29-31.

Zuckerman, R. (1972) Photoreceptor dark current: Role for an electrogenic sodium pump. Biophys. Soc. Abstr. 12: 101a. 